\title{
Effects of Mitochondrial DNA Deletion and OSW-1 on PI3K-AKT Signaling Pathway PCR Array in SK-Hep1 Cells
}

\author{
Xichen Du1 ${ }^{1}$ Changshi Qian², Xinglin Jin ${ }^{2 *}$ \\ ${ }^{1}$ Department of General Surgery, Affiliated Hospital of Jilin Medical University, Jilin, China \\ ${ }^{2}$ Department of Hepatopancreatobiliary Surgery, Affiliated Hospital of Yanbian University, Yanji, China \\ Email: *xljinyj@163.com
}

How to cite this paper: Du, X.C., Qian, C.S. and Jin, X.L. (2019) Effects of Mitochondrial DNA Deletion and OSW-1 on PI3K-AKT Signaling Pathway PCR Array in SK-Hep1 Cells. Chinese Medicine, 10, 107-119.

https://doi.org/10.4236/cm.2019.103006

Received: June 4, 2019

Accepted: September 23, 2019

Published: September 26, 2019

Copyright $\odot 2019$ by author(s) and Scientific Research Publishing Inc. This work is licensed under the Creative Commons Attribution International License (CC BY 4.0).

http://creativecommons.org/licenses/by/4.0/

\begin{abstract}
To investigate the effect of mitochondrial DNA deletion and OSW-1 on PI3K-AKT signaling pathway PCR Array in SK-Hep1 hepatocellular carcinoma cells, we prepared SK-Hep1 cells with mtDNA deletion, that is, $\mathrm{p}^{0} \mathrm{SK}$ Hep. Then the OSW-1 of $100 \mathrm{ng} / \mathrm{L}$ was used to intervene SK-Hep1 and $\mathrm{p}^{0} \mathrm{SK}-\mathrm{Hep} 1$. RT-qPCR was used to detect the difference of gene expression on PI3K-AKT signaling pathway PCR Array in four groups of cells. The gene expression of TLR4, FOS and TSC2 markers in SK-Hep1 cells treated with OSW-1 were significantly increased. The gene expressions of PDPK1, GJA1, TLR4 and TSC2 markers were significantly increased in $\mathrm{p}^{\circ}$ SK-Hep 1 cells, and the gene expressions of IRAK1 and GJA1 markers were significantly increased in $\mathrm{p}^{0}$ SK-Hep 1 cells treated with OSW-1. OSW-1 mainly affects the genes related to TLR4 pathway on PI3K-AKT signaling pathway PCR Array in SK-Hep1 HCC cells. $\mathrm{P}^{0}$ SK-Hep1 mainly affects the upstream PDK1 gene and downstream TSC2 gene of Akt on PI3K-AKT signaling pathway PCR Array, and also affects the gene expression of gap junction at the same time.
\end{abstract}

\section{Keywords \\ mtDNA, OSW-1, PI3K-AKT, PCR Array, SK-Hep1 Cells}

\section{Introduction}

Phosphatidylinositol-3 kinase (PI3K)-mediated signal transduction pathway is closely related to the occurrence and development of malignant tumors and plays an important role in the proliferation, migration and metabolism of tumor cells [1]. Activated AKT phosphorylated Bad, blocks the binding of Bad to Bcl-2 
or Bcl-xl to form a dimer and promotes the loss of apoptosis, thus promoting the survival of tumor cells [2]. Activated AKT can prevent the release of mitochondrial cytochrome $\mathrm{C}$ and apoptosis-inducing factor, and play an anti-apoptosis role [3].

In our previous study, $3 \beta, 16 \beta$,

$17 \alpha$-trihydroxycholest-5-en-22-one16-O-(2-O-4-methoxybenzoyl- $\beta$-Dxylopyran osyl)-(1 $\rightarrow 3)$-(2-O-acetyl- $\alpha$-L-arabinopyranoside) (OSW-1) inhibits the growth of tumor cells in the aspects of cell invasion, angiogenesis, cell polarity and cell adhesion, affects the core genes in each signaling pathway, and induces apoptosis of hepatoma cells [4]. OSW-1 swelled hepatoma cells and vacuolated the cytoplasm, nuclear dissolution and content overflow, a large number of lysosomes, cell membrane integrity destruction [5]. OSW-1 induced special apoptosis is different from the mitochondrial death pathway and the death receptor pathway and the final result is not Caspase family's activating [6]. So in this study, we prepared SK-Hep1 cells with mitochondrial DNA deletion, that is, $\mathrm{p}^{0} \mathrm{SK}-\mathrm{Hep} 1$, used real-time quantitative PCR(RT-qPCR) and detected the expression of PI3K-AKT signaling pathway PCR Array in order to clarify the effects of OSW-1 and mitochondrial DNA deletion on PI3K signaling pathway in hepatoma cells.

The complete combination of RT-PCR technology and gene chip technology is called PCR Array. PI3K-AKT signaling pathway PCR Array can simultaneously detect the expression of 84 genes related to PI3K-AKT signaling pathway. The new tablets include members of AKT (protein kinase B) and PI3K family and their regulatory genes. These genes are involved in many biological processes: Gsk3 inactivation, B-catenin deposition, actin assembly regulation and cell migration, BAD phosphorylation and so on. Genes related to IGF-1, mTOR and anti-apoptosis signaling pathway are also included.

\section{Materials and Methods}

1) Cell lines and main reagents. The human hepatoma cell line SK-Hep1 was obtained from the cell bank of the Chinese Academy of Sciences. sodium pyruvate, uridine were from Sigma (USA). Ethidium bromide (EB) was from DingGuo Biotechnology (China). TRIZOL ${ }^{\bullet}$ Reagent was from Invitrogen (USA). Chloroform, Isopropyl alcohol, 75\% Ethanol (in DEPC-treated water), RNase-free water were from Shanghai Chemical Reagent Co. Ltd. (China). RNase-free glycogen was from Ambion (USA).

2) Preparation and Identification of Hepatocellular carcinoma cells with Mitochondrial deletion ( $\left.p^{0} S K-H e p 1\right)$. SK-Hep1 cells were cultured in DMEM medium containing $10 \% \mathrm{FBS}, 100 \mathrm{U} / \mathrm{ml}$ penicillin, $100 \mathrm{ug} / \mathrm{ml}$ streptomycin, ethidium bromide $100 \mathrm{ug} / \mathrm{L}$, sodium pyruvate $100 \mathrm{mg} / \mathrm{L}$ and uracil nucleoside 50 $\mathrm{mg} / \mathrm{L}$, it was cultured at $37^{\circ} \mathrm{C}$ in $5 \% \mathrm{CO}_{2}$ incubator and subcultured once every 3 days to 21 generations. $3 \times 10^{5}$ cells per well were inoculated into the six-well culture plate and cultured in the medium without EB for 2 days. Because the growth process of mtDNA requires pyrimidine nucleoside and pyruvate to pro- 
vide energy to maintain, nutritional defects are used to identify the growth of mtDNA deletion cells. In the $\mathrm{p}^{0} \mathrm{SK}-\mathrm{Hep} 1$ cells cultured to logarithmic growth phase, the medium without pyruvate and uracil nucleoside was replaced, and the growth, morphological changes and death of the cells were observed, and SK-Hep1 cells were used as control. The living cells were identified by tabular blue exclusion method.

3) Detection of COX-I and COX-II by PCR amplification. To detect $\rho^{0}$ SK-Hep1completely lacking mtDNA, using COX-I and COX-II upstream primer, downstream primer. The result was detected by agarose gel electrophoresis.See our previous research for details [6].

4) RNA isolation, cDNA labeling Synthesis and Labeling and Expression profiling using microarray. RNA was converted into cDNA using Superscript Double-Stranded cDNA Synthesis Kit. The Labelled cRNAs were hybridized to the NimbleGen Human Gene Expression. See our previous research for details [6].

5) Date Analysis. $\Delta \Delta C t$ Method. 1). Calculate the $\Delta \mathrm{Ct}$ for each pathway-focused gene in each treatment group. $\Delta \mathrm{Ct}$ (group 1) = average $\mathrm{Ct}-$ average of $\mathrm{HK}$ genes' $\mathrm{Ct}$ for group 1 array $\Delta \mathrm{Ct}$ (group 2) = average $\mathrm{Ct}-$ average of $\mathrm{HK}$ genes' $\mathrm{Ct}$ for group 2 array. The expression level of the housekeeping genes chosen for normalization in the $\Delta \Delta \mathrm{Ct}$ method must not be influenced by your experimental conditions. If one or more such genes have been previously identified by independent means and if the PCR Array reproduces those results, use the average of their $\mathrm{Ct}$ values in the equation above. If an appropriate housekeeping gene has not been previously identified, use the average $\mathrm{Ct}$ value of all five housekeeping genes, but only if the difference in the average values between the two groups to be compared is less than one cycle. Otherwise, simply use zero in the place of the average of $\mathrm{HK}$ genes' $\mathrm{Ct}$ for each group to be compared, and rely on the consistency in the quantity and quality of your original input total RNA across your groups to effectively normalize your results. 2). Calculate the $\Delta \Delta \mathrm{Ct}$ for each gene across two PCR Arrays (or groups). $\Delta \Delta \mathrm{Ct}=\Delta \mathrm{Ct}$ (group 2) $-\Delta \mathrm{Ct}$ (group 1) Where group 1 is the control and group 2 is the experimental. 3). Calculate the fold-change for each gene from group 1 to group 2 as $2^{-\Delta \Delta C t}$. If the fold-change is greater than 1 , then the result may be reported as a fold up-regulation. If the fold-change is less than 1 , then the negative inverse of the result may be reported as a fold down-regulation.

\section{Results}

1) Culture medium and identification of $p^{0} S K$-Hep 1 cells. In the medium containing ethidium bromide without pyruvate and uracil, $\mathrm{p}^{0} \mathrm{SK}-\mathrm{Hep} 1$ cells were observed under inverted microscope to have a small amount of suspension and swelling on the first day, a large amount of suspension on the third day, independent non-aggregation of morphology and poor adhesion to the wall, almost all floated on the seventh day. The living cells were identified by tabular blue ex- 
clusion method, and the results showed that the living cells could not be found from the 6th day. In contrast, $\mathrm{p}^{0} \mathrm{SK}-\mathrm{Hep} 1$ cells rarely floated and grew normally in a medium supplemented with ethidium bromide, pyruvate and uracil (Figure 1(a), Figure 1(b)). Because the expression of COX-I and COX-II was inhibited in mitochondrial deletion cells, we determined whether mtDNA deletion cells were constructed by detecting COX-I and COX-II. In SK-Hep1 cells, COX-I, COX-II and GAPDH were expressed, but in $\mathrm{p}^{0} \mathrm{SK}-\mathrm{Hep} 1$ cells, COX-I and COX-II were almost not expressed (Figure 1(c), Figure 1(d)).

2) $S K$-Hepl treated with $O S W-1$ was compared with $S K-H e p 1$ in the PIBK pathway PCR Array. The expression of PI3K-AKT signaling pathway PCR Array in SK-Hep1 and SK-Hep1 treated with OSW-1 were detected by RT-qPCR method (see Figure 2, Figure 3). The expression of FOS, GRB2, HSPB1, IRAK1, PDPK1, PRKCA, PRKCB, TLR4, TOLLIP, TSC2 were up-regulated more than 2 times, especially in TLR4 (20.01 times), FOS (15.85 times), TSC2 (8.17 times). APC, IGF1, IRS1, PDGFRA, PTPN11, SHC1 were down-regulated more than 2 times. See Table 1 for details.

3) $p^{0} S K$-Hepl was compared with $S K$-Hepl in the PIBK pathway PCR Array. The expression of PI3K-AKT signaling pathway PCR Array in SK-Hep1 and $\mathrm{p}^{0}$ SK-Hep1 were detected by RT-qPCR method (see Figure 4). The expressions of CASP9, CD14, FOXO1, GJA1, GRB2, HSPB1, IGF1, MAPK3, DPK1, PRKCA,

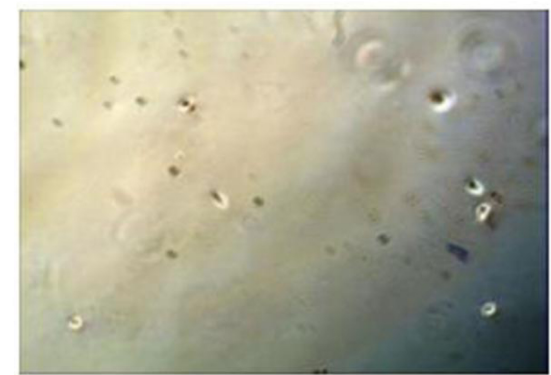

(a) SK-hep 1 coX-1 coX-2 coX-1 coX-2

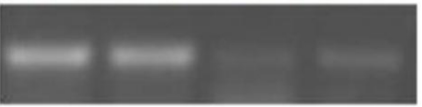

GAPDH

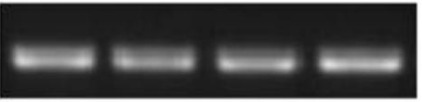

(c)

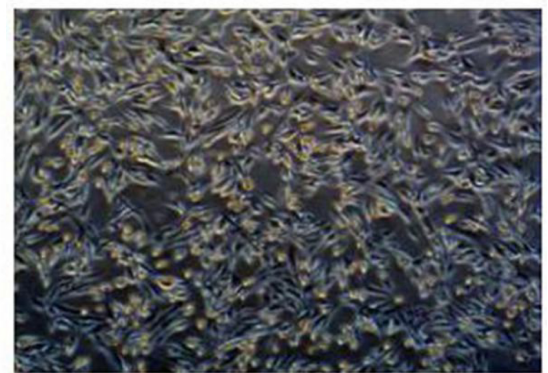

(b)

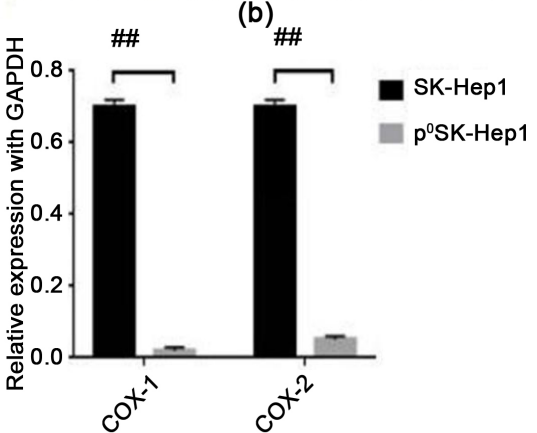

(d)

Figure 1. (a): $\mathrm{p}^{0} \mathrm{SK}-\mathrm{Hep} 1$ grew in the medium free of pyruvate and uracil nucleoside at the sixth day, there was almost no viable cells $(\times 40)$; (b): $\mathrm{p}^{0} \mathrm{SK}-\mathrm{Hep} 1$ grew in the medium containing EB, pyruvate and uracil nucleoside at the sixth day, and the cells were grown normally and attached $(\times 40)$. (c): Expression of COX-1 and COX-2mRNA in SK-Hep1 and $\mathrm{p}^{0}$ SK-Hep1cells by RT-PCR, COX-1 mRNA and COX-2 mRNA were expressed normally in SK-Hep1, but in $\mathrm{p}^{0} \mathrm{SK}-\mathrm{Hep} 1$ were hardly expressed; (d): Histogram of COX-1 and COX-2 expression in SK-Hep1 and $\mathrm{p}^{0}$ SK-Hep1 cells. (\#\#: $\left.<<0.01\right)$ 
X. C. Du et al.

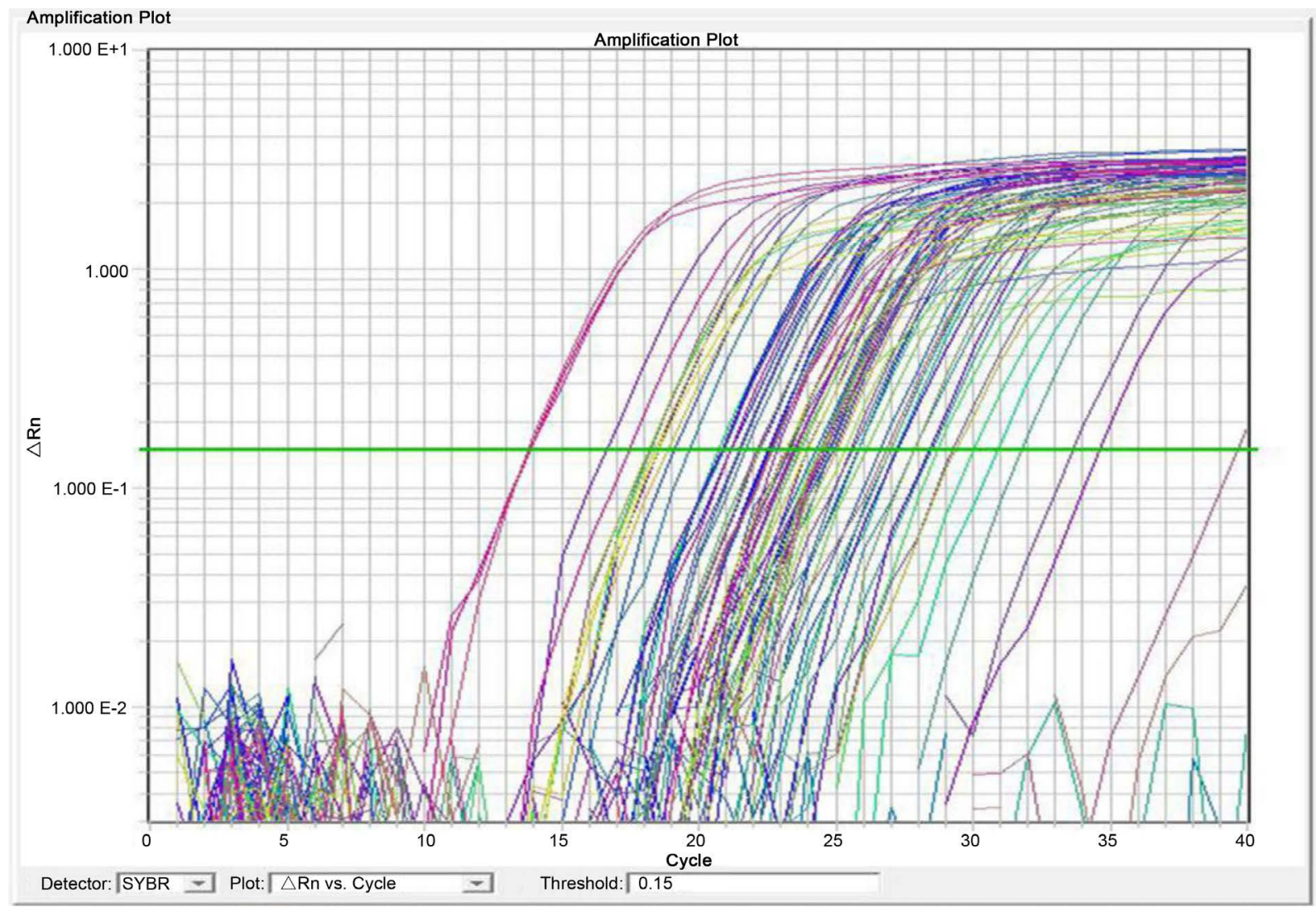

Figure 2. The expression of PI3K-AKT signaling pathway PCR Array in SK -Hep1wasdetected by RT-qPCR.

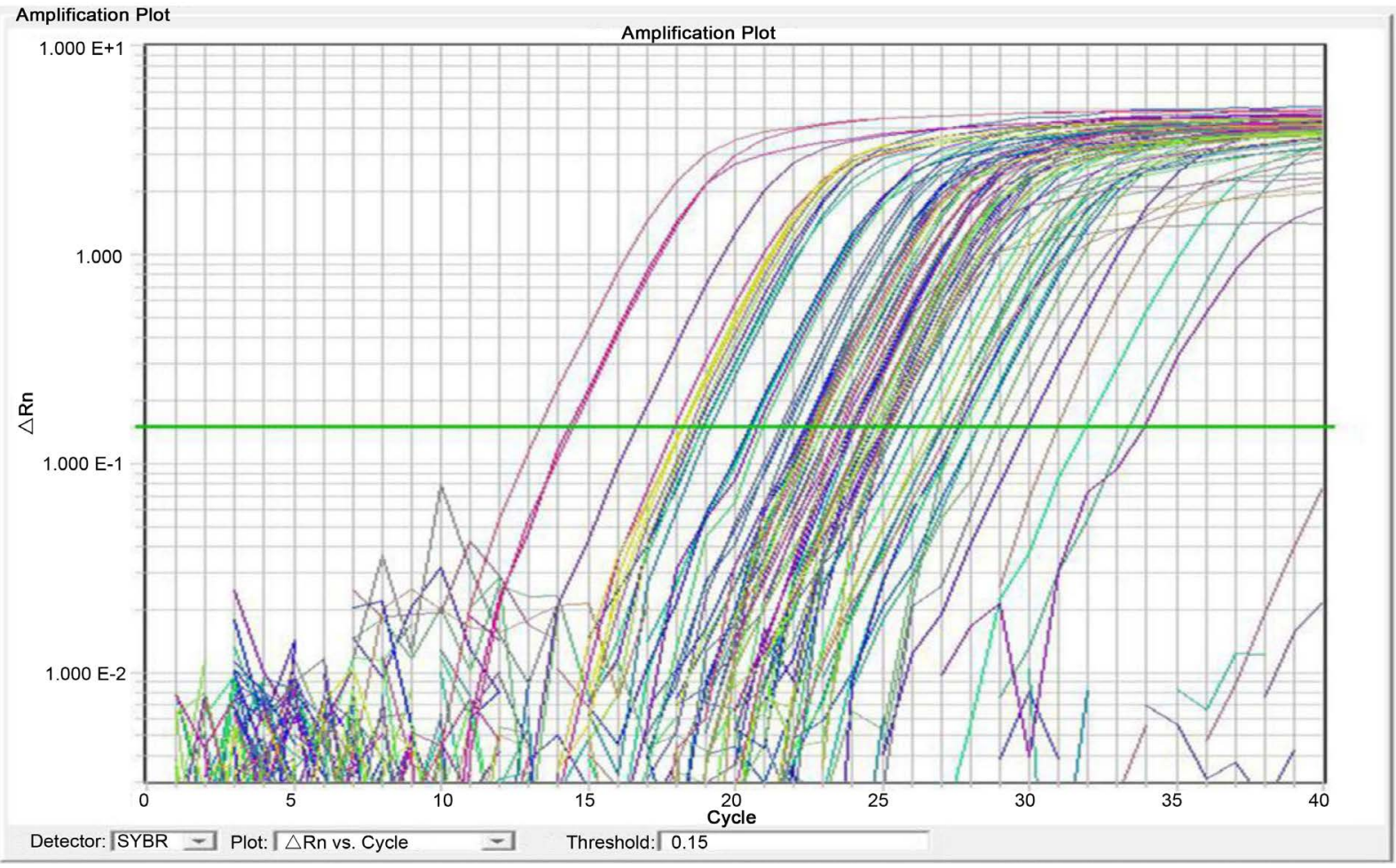

Figure 3. The expression of PI3K-AKT signaling pathway PCR Array in SK-Hep1 treated with OSW-1 was detected by RT-qPCR. 
X. C. Du et al.

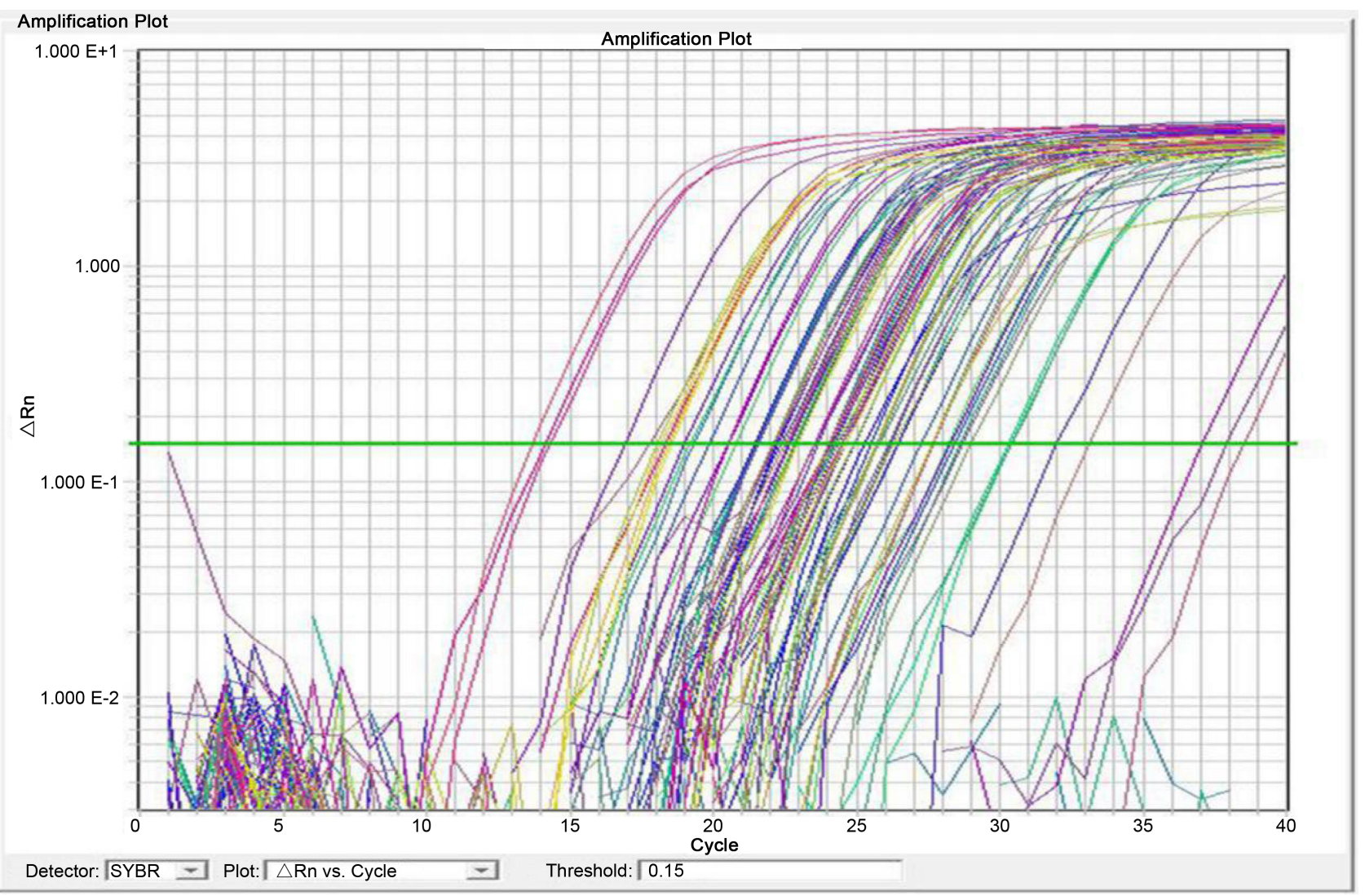

Figure 4. The expression of PI3K-AKT signaling pathway PCR Array in p0SK-Hep1 was detected by RT-qPCR.

Table 1. SK-Hep1 treated with OSW-1 was compared with SK-Hep1 in the PI3K pathway PCR Array.

\begin{tabular}{|c|c|c|c|c|c|c|}
\hline \multirow{2}{*}{ Symbol } & \multicolumn{2}{|c|}{ AVG $\Delta \mathrm{C}_{\mathrm{t}}(\mathrm{Ct}(\mathrm{GOI})-\operatorname{Ave} \mathrm{Ct}(\mathrm{HKG}))$} & \multicolumn{2}{|c|}{$2 \Delta-\Delta \mathrm{Ct}$} & \multirow{2}{*}{$\begin{array}{c}\text { Fold Change } \\
\text { SK-Hep1+OSW1/SK-Hep1 }\end{array}$} & \multirow{2}{*}{$\begin{array}{c}\begin{array}{c}\text { Fold up - or Down } \\
\text { regulation }\end{array} \\
\text { SK-Hep1+OSW1/SK-Hep1 }\end{array}$} \\
\hline & SK-Hep1+OSW1 & SK-Hep1 & SK-Hep1+OSW1 & SK-Hep1 & & \\
\hline APC & 11.73 & 10.63 & $2.9 \mathrm{E}-04$ & $6.3 \mathrm{E}-04$ & 0.47 & -2.15 \\
\hline FOS & 9.67 & 13.66 & $1.2 \mathrm{E}-03$ & $7.7 \mathrm{E}-05$ & 15.85 & 15.85 \\
\hline GRB2 & 5.20 & 6.84 & $2.7 \mathrm{E}-02$ & 8.7E-03 & 3.11 & 3.11 \\
\hline HSPB1 & 10.36 & 11.51 & $7.6 \mathrm{E}-04$ & $3.4 \mathrm{E}-04$ & 2.23 & 2.23 \\
\hline IGF1 & 16.86 & 15.48 & $8.4 \mathrm{E}-06$ & $2.2 \mathrm{E}-05$ & 0.39 & -2.59 \\
\hline IRAK1 & 11.15 & 12.37 & $4.4 \mathrm{E}-04$ & $1.9 \mathrm{E}-04$ & 2.32 & 2.32 \\
\hline IRS1 & 13.32 & 12.10 & $9.8 \mathrm{E}-05$ & $2.3 \mathrm{E}-04$ & 0.43 & -2.34 \\
\hline PDGFRA & 18.36 & 17.36 & $3.0 \mathrm{E}-06$ & $5.9 \mathrm{E}-06$ & 0.5 & -2 \\
\hline PDPK1 & 7.60 & 9.31 & $5.1 \mathrm{E}-03$ & $1.6 \mathrm{E}-03$ & 3.26 & 3.26 \\
\hline PRKCA & 6.48 & 8.08 & $1.1 \mathrm{E}-02$ & $3.7 \mathrm{E}-03$ & 3.04 & 3.04 \\
\hline PRKCB & 17.16 & 18.23 & $6.8 \mathrm{E}-06$ & $3.2 \mathrm{E}-06$ & 2.1 & 2.1 \\
\hline PTPN11 & 8.40 & 7.22 & $3.0 \mathrm{E}-03$ & $6.7 \mathrm{E}-03$ & 0.44 & -2.26 \\
\hline SHC1 & 6.74 & 4.85 & $9.4 \mathrm{E}-03$ & $3.5 \mathrm{E}-02$ & 0.27 & -3.69 \\
\hline TLR4 & 14.33 & 18.66 & $4.8 \mathrm{E}-05$ & $2.4 \mathrm{E}-06$ & 20.01 & 20.01 \\
\hline TOLLIP & 6.85 & 8.17 & $8.7 \mathrm{E}-03$ & $3.5 \mathrm{E}-03$ & 2.5 & 2.5 \\
\hline TSC2 & 10.02 & 13.05 & $9.6 \mathrm{E}-04$ & $1.2 \mathrm{E}-04$ & 8.17 & 8.17 \\
\hline
\end{tabular}


RPS6KA1, TLR4 and TSC2 were up-regulated more than 2 times, especially inPDPK1 (13.27 times), GJA1 (9.67 times), TLR4 (4.42 times) and TSC2 (4.37 times). Only APC and CTNNB1 were down-regulated more than 2 times. See Table 2 for details.

4) p0SK-Hepl treated with OSW-1 was compared with $S K$-Hep1 in the PIBK pathway PCR Array. The expression of PI3K-AKT signaling pathway PCR Array in SK-Hep1 and $\mathrm{p}^{0}$ SK-Hep1treated with OSW-1were detected by RT-qPCR method (see Figure 5) (Table 3). The expressions of AKT1 CD14 CDKN1B FASLG GJA1 GRB2 HSPB1 IRAK1 IRS1 MAPK3 PDR2 PDPK1 PIK3R2 PRKCA PRKCB RPS6KA1 SHC1 SRF TOLLIP TSC2 were up-regulated more than 2 times, especially in IRAK1 (101.93 times) and GJA1 (7.62 times). The expression of APC CHUK MTCP1 PAR1 PDK1 PIK3CG RASA1 RPS6KB1 SOS1 WASL were down-regulated more than 2 times, especially PIK3CG was 4.15 times lower. See Table 3 for details.

\section{Discussion}

Most primary hepatocellular carcinoma (HCC) is associated with inflammation and cirrhosis [7]. Chronic injury and inflammation are closely related to tumorigenesis [8]. TLR4 in TLRs family is one of the important members that regulate the immune response and inflammatory reaction, TLR4 activates downstream signal transduction elements through two downstream pathways MyD88-dependent and MyD88-independent to induce apoptosis and necroptosis [9]. TLRs signaling pathway promotes the production of related cytokines by

Table 2. p0SK-Hep1 was compared with SK-Hep1 in the PI3K pathway PCR Array.

\begin{tabular}{ccccccc}
\hline \multirow{2}{*}{ Symbol } & \multirow{2}{*}{ AVG $\Delta \mathrm{C}_{\mathrm{t}}(\mathrm{Ct}(\mathrm{GOI})$-Ave Ct(HKG) } & \multicolumn{2}{c}{$2 \Delta-\Delta \mathrm{Ct}$} & Fold Change & Fold up - or Down regulation \\
\cline { 2 - 6 } & p0SK-Hep1 & SK-Hep1 & p0SK-Hep1 & SK-Hep1 & p0SK-Hep1/SK-Hep1 & p0SK-Hep1/SK-Hep1 \\
\hline APC & 11.80 & 10.63 & $2.8 \mathrm{E}-04$ & $6.3 \mathrm{E}-04$ & 0.44 & -2.25 \\
CASP9 & 7.41 & 8.42 & $5.9 \mathrm{E}-03$ & $2.9 \mathrm{E}-03$ & 2.01 & 2.01 \\
CD14 & 9.78 & 10.87 & $1.1 \mathrm{E}-03$ & $5.3 \mathrm{E}-04$ & 2.13 & 2.13 \\
CTNNB1 & 6.02 & 4.89 & $1.5 \mathrm{E}-02$ & $3.4 \mathrm{E}-02$ & 0.46 & -2.19 \\
FOXO1 & 9.77 & 10.91 & $1.1 \mathrm{E}-03$ & $5.2 \mathrm{E}-04$ & 2.2 & 2.2 \\
GJA1 & 15.38 & 18.66 & $2.3 \mathrm{E}-05$ & $2.4 \mathrm{E}-06$ & 9.67 & 9.67 \\
GRB2 & 5.57 & 6.84 & $2.1 \mathrm{E}-02$ & $8.7 \mathrm{E}-03$ & 2.4 & 2.4 \\
HSPB1 & 9.10 & 11.51 & $1.8 \mathrm{E}-03$ & $3.4 \mathrm{E}-04$ & 5.32 & 5.32 \\
IGF1 & 13.82 & 15.48 & $6.9 \mathrm{E}-05$ & $2.2 \mathrm{E}-05$ & 3.17 & 3.17 \\
MAPK3 & 6.16 & 7.28 & $1.4 \mathrm{E}-02$ & $6.4 \mathrm{E}-03$ & 2.16 & 2.16 \\
PDPK1 & 5.58 & 9.31 & $2.1 \mathrm{E}-02$ & $1.6 \mathrm{E}-03$ & 13.27 & 13.27 \\
PRKCA & 6.19 & 8.08 & $1.4 \mathrm{E}-02$ & $6.4 \mathrm{E}-03$ & 2.16 & 2.16 \\
RPS6KA1 & 7.72 & 8.82 & $4.7 \mathrm{E}-03$ & $2.2 \mathrm{E}-03$ & 2.15 & 4.16 \\
TLR4 & 16.51 & 18.66 & $1.1 \mathrm{E}-05$ & $2.4 \mathrm{E}-06$ & 4.42 & \\
TSC2 & 10.92 & 13.05 & $5.2 \mathrm{E}-04$ & $1.2 \mathrm{E}-04$ & 4.37 & \\
\hline
\end{tabular}


Table 3. p0SK-Hep1 treated with OSW-1 was compared with SK-Hep1 in the PI3K pathway PCR Array.

\begin{tabular}{|c|c|c|c|c|c|c|}
\hline \multirow[t]{2}{*}{ Symbol } & \multicolumn{2}{|c|}{$\begin{array}{c}\text { AVG } \Delta \mathrm{C}_{\mathrm{t}}(\mathrm{Ct}(\mathrm{GOI})-\text { Ave } \\
\mathrm{Ct}(\mathrm{HKG}))\end{array}$} & \multicolumn{2}{|l|}{$2 \Delta-\Delta \mathrm{Ct}$} & \multirow{2}{*}{$\begin{array}{c}\text { Fold Change } \\
\text { p0SK-Hep1+OSW1/SK-Hep1 }\end{array}$} & \multirow{2}{*}{$\begin{array}{c}\begin{array}{c}\text { Fold up - or Down } \\
\text { regulation }\end{array} \\
\text { p0SK-Hep1+OSW1/SK-Hep1 }\end{array}$} \\
\hline & p0SK-Hep1+OSW1 & SK-Hep1 & p0SK-Hep1+OSW1 & SK-Hep1 & & \\
\hline AKT1 & 6.85 & 8.22 & $8.7 \mathrm{E}-03$ & $3.4 \mathrm{E}-03$ & 2.58 & 2.58 \\
\hline APC & 12.16 & 10.63 & $2.2 \mathrm{E}-04$ & $6.3 \mathrm{E}-04$ & 0.35 & -2.89 \\
\hline CD14 & 8.83 & 10.87 & $2.2 \mathrm{E}-03$ & $5.3 \mathrm{E}-04$ & 4.12 & 4.12 \\
\hline CDKN1B & 12.12 & 14.54 & $2.2 \mathrm{E}-04$ & $4.2 \mathrm{E}-05$ & 5.34 & 5.34 \\
\hline FASLG & 16.75 & 18.66 & $9.1 \mathrm{E}-06$ & $2.4 \mathrm{E}-06$ & 3.75 & 3.75 \\
\hline GJA1 & 15.73 & 18.66 & $1.8 \mathrm{E}-05$ & $2.4 \mathrm{E}-06$ & 7.62 & 7.62 \\
\hline GRB2 & 5.15 & 6.84 & $2.8 \mathrm{E}-02$ & $8.7 \mathrm{E}-03$ & 3.23 & 3.23 \\
\hline HSPB1 & 9.31 & 11.51 & $1.6 \mathrm{E}-03$ & $3.4 \mathrm{E}-04$ & 4.6 & 4.6 \\
\hline IRAK1 & 5.70 & 12.37 & $1.9 \mathrm{E}-02$ & $1.9 \mathrm{E}-04$ & 101.93 & 101.93 \\
\hline IRS1 & 10.63 & 12.10 & $6.3 \mathrm{E}-04$ & $2.3 \mathrm{E}-04$ & 2.77 & 2.77 \\
\hline MAPK3 & 5.54 & 7.28 & $2.1 \mathrm{E}-02$ & $6.4 \mathrm{E}-03$ & 3.33 & 3.33 \\
\hline MTCP1 & 11.65 & 10.64 & $3.1 \mathrm{E}-04$ & $6.3 \mathrm{E}-04$ & 0.5 & -2.01 \\
\hline PAK1 & 9.05 & 7.71 & $1.9 \mathrm{E}-03$ & $4.8 \mathrm{E}-03$ & 0.4 & -2.53 \\
\hline PDK1 & 11.05 & 9.18 & $4.7 \mathrm{E}-04$ & $1.7 \mathrm{E}-03$ & 0.27 & -3.67 \\
\hline PDK2 & 10.44 & 12.95 & $7.2 \mathrm{E}-04$ & $1.3 \mathrm{E}-04$ & 5.72 & 5.72 \\
\hline PDPK1 & 6.62 & 9.31 & $1.0 \mathrm{E}-02$ & $1.6 \mathrm{E}-03$ & 6.46 & 6.46 \\
\hline PIK3CG & 13.56 & 11.50 & $8.3 \mathrm{E}-05$ & $3.4 \mathrm{E}-04$ & 0.24 & -4.15 \\
\hline PIK3R2 & 8.51 & 9.75 & $2.8 \mathrm{E}-03$ & $1.2 \mathrm{E}-03$ & 2.38 & 2.38 \\
\hline PRKCA & 6.48 & 8.08 & $1.1 \mathrm{E}-02$ & $3.7 \mathrm{E}-03$ & 3.02 & 3.02 \\
\hline PRKCB & 16.48 & 18.23 & $1.1 \mathrm{E}-05$ & $3.2 \mathrm{E}-06$ & 3.37 & 3.37 \\
\hline RASA1 & 7.06 & 5.91 & $7.5 \mathrm{E}-03$ & $1.7 \mathrm{E}-02$ & 0.45 & -2.22 \\
\hline RPS6KA1 & 7.31 & 8.82 & $6.3 \mathrm{E}-03$ & $2.2 \mathrm{E}-03$ & 2.85 & 2.85 \\
\hline RPS6KB1 & 8.38 & 7.23 & $3.0 \mathrm{E}-03$ & $6.7 \mathrm{E}-03$ & 0.45 & -2.15 \\
\hline SHC1 & 2.55 & 4.85 & $1.7 \mathrm{E}-01$ & $3.5 \mathrm{E}-02$ & 4.89 & 4.89 \\
\hline SOS1 & 8.00 & 6.90 & $3.9 \mathrm{E}-03$ & $8.4 \mathrm{E}-03$ & 0.47 & -2.15 \\
\hline SRF & 6.95 & 8.33 & $8.1 \mathrm{E}-03$ & $3.1 \mathrm{E}-03$ & 2.61 & 2.61 \\
\hline TOLLIP & 6.30 & 8.17 & $1.3 \mathrm{E}-02$ & $3.5 \mathrm{E}-03$ & 3.64 & 3.64 \\
\hline TSC2 & 10.09 & 13.05 & $9.2 \mathrm{E}-04$ & $1.2 \mathrm{E}-04$ & 7.78 & 7.78 \\
\hline WASL & 9.31 & 7.61 & $1.6 \mathrm{E}-03$ & $5.1 \mathrm{E}-03$ & 0.31 & -3.26 \\
\hline
\end{tabular}

integrating connecting molecules such as MyD88 and tumor necrosis factor receptor related molecule 6 (TRAF6), and finally activates AP-1 and NF-kappa B [10]. AP-1 can affect inflammatory response by regulating the activity of innate immune system [11]. As a molecular switch to initiate gene transcription, AP-1 regulates gene expression through various conditions such as cell stress stimulation, and participates in a variety of cellular processes, such as proliferation, differentiation, apoptosis, transformation, cell migration, inflammation and wound healing. Transcription factor AP-1 is a dimer complex, which is composed of 


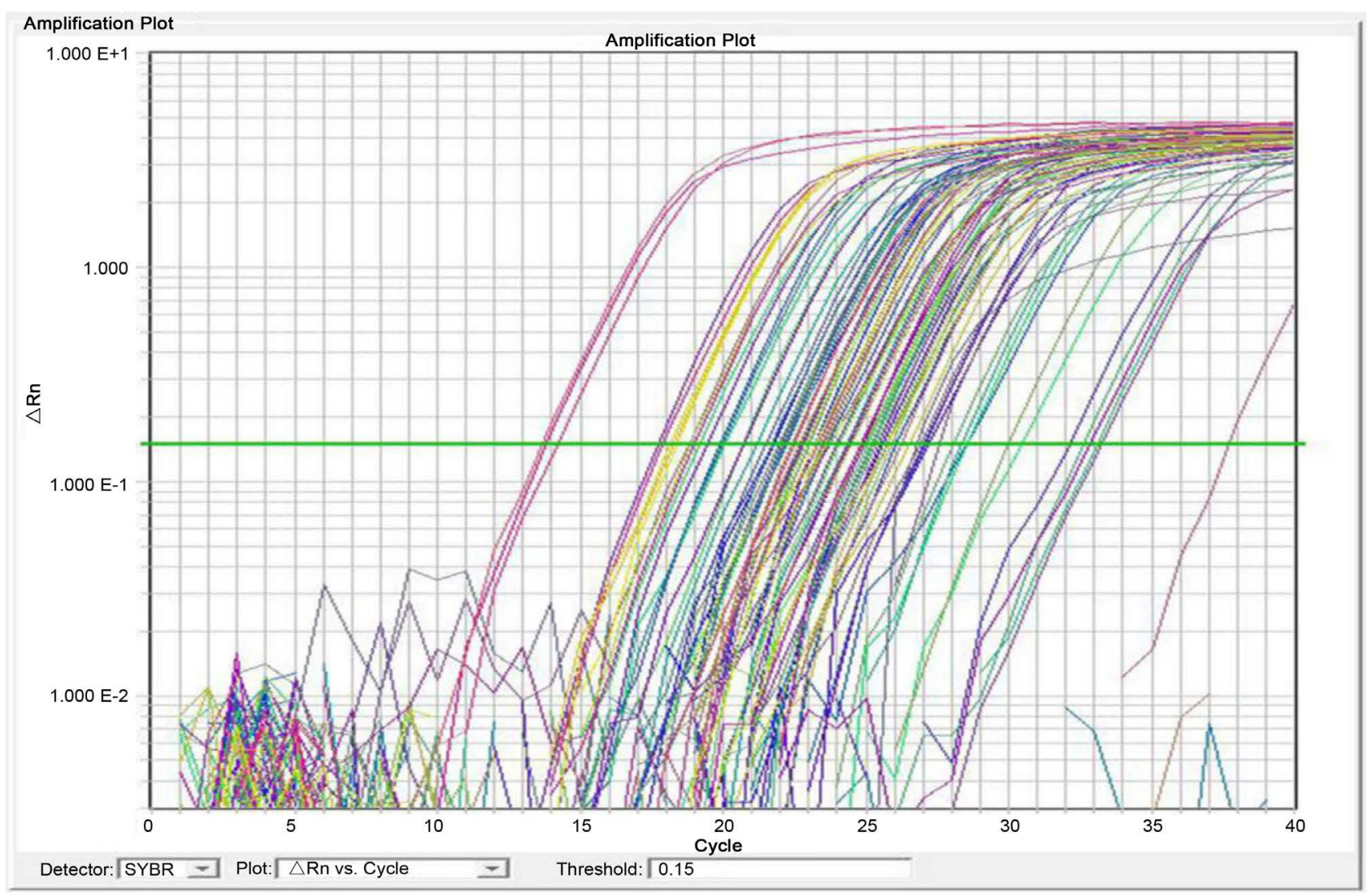

Figure 5. The expressions of PI3K-AKT signaling pathway PCR Array in $\mathrm{p}^{0}$ SK-Hep1 treated with OSW-1 were detected by RT-qPCR method.

Jun family and Fos family proteins encoded by proto-oncogenes. Fos and Jun form heterodimer [12]. Among the many AP-1 dimers, AP-1 heterodimer formed by Fos and Jun is the most stable [13]. AP-1 plays a dual role in regulating apoptosis. AP-1 can promote or inhibit apoptosis in different cells. Different signal pathways are involved in the pathogenesis of HCC, and the inflammatory signal pathway is closely related to the occurrence and development of HCC [14] [15]. The role of IRAK1 in different tumors has been widely concerned [16] [17], IRAK1 is a downstream signal molecule of activated MyD88 recruitment, which can activate FADD to induce apoptosis. IRAK1 can also activateTRAF6 induce the expression of downstream specific genes.IRAK1 is an essential factor in the induction of mitochondrial division and necroptosis [18]. IRAK 1 is related to the formation and development of tumors, is an important tumor target [19]. Infinite proliferation is an important feature of most malignant tumors, including hepatocellular carcinoma [20] [21]. The results showed that the TLR4 and FOS genes were significantly increased by OSW-1 in SK-Hep1 HCC cells, and the IRAK1 type genes were significantly increased by $\mathrm{p}^{0} \mathrm{SK} / \mathrm{Hep} 1$ induced by OSW-1. Therefore, we predict that OSW-1 has a significant effect on TLR4 signaling pathway in SK-Hep1 HCC cells and induce apoptosis and necrotic apoptosis in HCC cells.

The PDPK1 marker genes in the PCR chip of PI3K gene represent PDK1 and 
PDPK2 genes. PDK1 is an important kinase in PI3K/Akt pathway. PDK1 plays an important role in cell growth, proliferation, metabolism and survival [22]. PDK1 can be activated by binding to PIP3 on the plasma membrane. As an upstream regulatory molecule of Akt, activated PDK1 can phosphorylate Akt, activate Akt [23], and activate Akt to transmit intracellular signals downstream by phosphorylation of its downstream protein TSC2. In order to regulate the biological processes such as glycogen and protein synthesis and cell growth and proliferation. When TSC2 mutates, it can affect the intracellular signal transmission, resulting in the dysfunction of cell function. When lack of energy, the level of AMP in the body increases, and then the activated AMPK of AMPK, acts on the gene TSC1/TSC2 [24], which binds to the C terminal of TSC2 and enhances the activity of TSC2, thus inhibiting the activity of $\mathrm{m}$ TOR. Inhibit apoptosis caused by glucose deficiency and enhance the survivability of cells [25].

The GJA1 marker gene in the PCR chip of PI3K gene represents the gap junction protein. There are defects of gap junction communication function and abnormal expression of gap junction protein in tumor cells. Gap junction protein can form gap junction channel and mediate the exchange of information between cells [26], which is widely expressed in various types of human cells, in which the abnormal expression of $\mathrm{Cx} 43$ is closely related to the occurrence and development of tumor [27]. In hepatocellular carcinoma (hepatocellular carcinoma, HCC), the expression of $\mathrm{Cx} 43$ in patients with distant metastasis was lower than that in patients without metastasis or liver metastasis, and the expression of $\mathrm{Cx} 43 \mathrm{mRNA}$ in patients with early recurrence was lower than that in patients without recurrence [28]. Cx43 exists not only in cell membrane [29], but also in the mitochondrial intima [30]. Cx43 was transported to the inner membrane of mitochondria through the general outer membrane transporter/intimal transporter pathway, and the transport pathway depended on the cytoplasmic chaperone heat shock protein 90 [31]. Our results show that the deletion of mitochondrial DNA leads to the increase of the expression level of gap junction protein in SK-Hep1 hepatocellular carcinoma cells. The deletion of mitochondrial DNA also increased the gene expression of PDPK1 and TSC2 markers in SK-Hep1 HCC cells.

\section{Conclusion}

As a classical signal pathway, PI3K/Akt plays an important role in cell proliferation, differentiation, survival and migration, and is also the main target of drug development in many diseases. OSW-1 mainly affects the genes related to TLR4 pathway on PI3K-AKT signaling pathway PCR Array in SK-Hep1 HCC cells. $\mathrm{P}^{0}$ SK-Hep1 mainly affects the upstream PDK1 gene and downstream TSC2 gene of Akt on PI3K-AKT signaling pathway PCR Array, and also affects the gene expression of gap junction at the same time.

\section{Conflicts of Interest}

The authors declare no conflicts of interest regarding the publication of this paper. 


\section{References}

[1] Hanahan, D. and Weinberg, R.A. (2011) Hallmarks of Cancer: The Next Generation. Cell, 144, 646-674. https://doi.org/10.1016/j.cell.2011.02.013

[2] Yang, J., Zou, Y. and Jiang, D. (2018) Honokiol Suppresses Proliferation and Induces Apoptosis via Regulation of the miR-21/PTEN/PI3K/AKT Signaling Pathway in Human Osteosarcoma Cells. International Journal of Molecular Medicine, 41, 1845-1854.

[3] Kumar, D., Haldar, S., Gorain, M., et al. (2018) Epoxyazadiradione Suppresses Breast Tumor Growth through Mitochondrial Depolarization and Caspase-Dependent Apoptosis by Targeting PI3K/Akt Pathway. BMC Cancer, 18, 52-69. https://doi.org/10.1186/s12885-017-3876-2

[4] Jin, J.C., Jin, X.L., Qian, C.S., et al. (2013) Signaling Network of OSW-1-Induced Apoptosis and Necroptosis in Hepatocellular Carcinoma. Molecular Medicine Reports, 7, 1646-1650. https://doi.org/10.3892/mmr.2013.1366

[5] Jin, J.C., Jin, X.L., Zhang, X., et al. (2013) Effect of OSW-1 on microRNA Expression Profiles of Hepatoma Cells and Functions of Novel microRNAs. Molecular Medicine Reports, 7, 1831-1837. https://doi.org/10.3892/mmr.2013.1428

[6] Liu, X.C., Liang, J.C., Jin, J.C., et al. (2017) OSW-1 Induced Apoptosis in Hepatocellular Carcinoma through Generation of ROS, Cytochrome C and Noxa Activation Independent of p53 with Non-Activation of Caspase-3. Chinese Medicine, 8, 1-9. https://doi.org/10.4236/cm.2017.81001

[7] Wan, X.W., Jiang, M., Cao, H.F., et al. (2003) The Alteration of PTEN Tumor Suppressor Expression and Its Association with the Histopathological Features of $\mathrm{Hu}$ man Primary Hepatocellular Carcinoma. Journal of Cancer Research and Clinical Oncology, 129, 100-106.

[8] El-Serag, H.B. and Rudolph, K.L. (2007) Hepatocellular Carcinoma: Epidemiology and Molecular Carcinogenesis. Gastroenterology, 132, 2557-2576.

https://doi.org/10.1053/j.gastro.2007.04.061

[9] Akira, S. and Takeda, K. (2004) Toll-Like Receptor Signaling. Nature Reviews Immunology, 4, 499-511. https://doi.org/10.1038/nri1391

[10] Roy, A., Srivastava, M., Saqib, U., et al. (2016) Potential Therapeutic Targets for Inflammation in Toll-Like Receptor 4 (TLR4)-Mediated Signaling Pathways. International Immunopharmacology, 40, 79-89. https://doi.org/10.1016/j.intimp.2016.08.026

[11] Ratajczak-Wrona, W., Jablonska, E., Garley, M.A., et al. (2013) Role of AP-1 Family Proteins in Regulation of Inducible Nitric Oxide Synthase (iNOS) in Human Neutrophils. Journal of Immunotoxicology, 10, 32-39. https://doi.org/10.3109/1547691X.2012.686929

[12] Hess, J., Angel, P. and Schorpp-Kistner, M. (2004) AP-1 Subunits: Quarrel and Harmony among Siblings. Journal of Cell Science, 117, 5965-5973.

https://doi.org/10.1242/jcs.01589

[13] Jia, J., Ye, T., Cui, P., Hua, Q., Zeng, H. and Zhao, D. (2016) AP-1 Transcription Factor Mediates VEGF-Induced Endothelial Cell Migration and Proliferation. Microvascular Research, 105, 103-108. https://doi.org/10.1016/j.mvr.2016.02.004

[14] Li, X., Liu, C., Ip, B.C., et al. (2015) Tumor Progression Locus 2 Ablation Suppressed Hepatocellular Carcinoma Development by Inhibiting Hepatic Inflammation and Steatosis in Mice. Journal of Experimental \& Clinical Cancer Research, 34, 138. https://doi.org/10.1186/s13046-015-0254-2 
[15] Li, L., Xu, L., Yan, J., et al. (2015) CXCR2-CXCL1 Axis Is Correlated with Neutrophil Infiltration and Predicts a Poor Prognosis in Hepatocellular Carcinoma. Journal of Experimental \& Clinical Cancer Research, 34, 129. https://doi.org/10.1186/s13046-015-0247-1

[16] Zhang, X., Dang, Y., Li, P., Rong, M. and Chen, G. (2014) Expression of IRAK1 in Lung Cancer Tissues and Its Clinicopathological Significance: A Microarray Study. International Journal of Clinical and Experimental Pathology, 7, 8096-8104.

[17] Wee, Z.N., Yatim, S.M., Kohlbauer, V.K., et al. (2015) IRAK1 Is a Therapeutic Target That Drives Breast Cancer Metastasis and Resistance to Paclitaxel. Nature Communications, 6, Article No. 8746. https://doi.org/10.1038/ncomms9746

[18] Baker, B., Maitra, U., Geng, S. and Li, L. (2014) Molecular and Cellular Mechanisms Responsible for Cellular Stress and Low-Grade Inflammation Induced by a Super-Low Dose of Endotoxin. The Journal of Biological Chemistry, 289, 16262-16269. https://doi.org/10.1074/jbc.M114.569210

[19] Rhyasen, G.W. and Starczynowski, D.T. (2015) IRAK Signalling in Cancer. British Journal of Cancer, 112, 232-237. https://doi.org/10.1038/bjc.2014.513

[20] Feitelson, M.A., Arzumanyan, A., Kulathinal, R.J., et al. (2015) Sustained Proliferation in Cancer: Mechanisms and Novel Therapeutic Targets. Seminars in Cancer Biology, 35, S25-S54. https://doi.org/10.1016/j.semcancer.2015.02.006

[21] Deng, L., Yang, H., Tang, J., et al. (2015) Inhibition of MTA1 by ERalpha Contributes to Protection Hepatocellular Carcinoma from Tumor Proliferation and Metastasis. Journal of Experimental \& Clinical Cancer Research, 34, 128. https://doi.org/10.1186/s13046-015-0248-0

[22] Ito, K., Akazawa, H., Tamagawa, M., et al. (2009) PDK1 Coordinates Survival Pathways and Beta-Adrenergic Response in the Heart. Proceedings of the National Academy of Sciences of the United States of America, 106, 8689-8694. https://doi.org/10.1073/pnas.0900064106

[23] Toker, A. and Newton, A.C. (2000) Cellular Signaling: Pivoting around PDK-1. Cell, 103, 185-188. https://doi.org/10.1016/S0092-8674(00)00110-0

[24] van Veelen, W., Korsse, S.E., van de Laar, L., et al. (2011) The Long and Winding Road to Rational Treatment of Cancer Associated with LKB1/AMPK/TSC/m TORC1 Signaling. Oncogene, 30, 2289-2303. https://doi.org/10.1038/onc.2010.630

[25] Saito, K., Araki, Y., Kontani, K., et al. (2005) Novel Role of the Small GTPaseRheb: Its Implication in Endocytic Pathway Independent of the Activation of Mammalian Target of Rapamycin. Journal of Biochemistry, 137, 423-430. https://doi.org/10.1093/jb/mvi046

[26] Qiu, X., Cheng, J.C., Klausen, C., et al. (2016) EGF-Induced Connexin43 Negatively Regulates Cell Proliferation in Human Ovarian Cancer. Journal of Cellular Physiology, 231, 111-119. https://doi.org/10.1002/jcp.25058

[27] Forster, T., Rausch, V., Zhang, Y., et al. (2014) Sulforaphane Counteracts Aggressiveness of Pancreatic Cancer Driven by Dysregulated Cx43-Mediated Gap Junctional Intercellular Communication. Oncotarget, 5, 1621-1634. https://doi.org/10.18632/oncotarget.1764

[28] Wang, Z.S., Wu, L.Q., Yi, X., et al. (2013) Connexin-43 Can Delay Early Recurrence and Metastasis in Patients with Hepatitis B-Related Hepatocellular Carcinoma and Low Serum Alpha-Fetoprotein after Radical Hepatectomy. BMC Cancer, 13, 306. https://doi.org/10.1186/1471-2407-13-306

[29] Saez, J.C., Berthoud, V.M., Branes, M.C., et al. (2003) Plasma Membrane Channels Formed by Connexins: Their Regulation and Functions. Physiological Reviews, 83, 
1359-1400. https://doi.org/10.1152/physrev.00007.2003

[30] Boengler, K., Stahlhofen, S., van de Sand, A., et al. (2009) Presence of Connexin 43 in Subsarcolemmal, But Not in Interfibrillar Cardiomyocyte Mitochondria. Basic Research in Cardiology, 104, 141-147. https://doi.org/10.1007/s00395-009-0007-5

[31] Rodriguez-Sinovas, A., Boengler, K., Cabestrero, A., et al. (2006) Translocation of Connexin43 to the Inner Mitochondrial Membrane of Cardiomyocytes through the Heat Shock Protein 90-Dependent TOM Pathway and Its Importance for Cardioprotection. Circulation Research, 99, 93-101.

https://doi.org/10.1161/01.RES.0000230315.56904.de 